\title{
Medio siglo (1956-2005) de crecimiento urbano y pérdida de suelo en el litoral mediterráneo español. El entorno metropolitano de Alacant-Elx
}

\author{
Antonio Valera Lozano \\ Carlos Añó Vidal \\ Juan Sánchez Díaz \\ Universitat de València \\ Centro de Investigaciones sobre Desertificación - CIDE \\ antonio.valera@uv.es \\ carlos.anyo@uv.es \\ juan.sanchez@uv.es
}

\section{Resumen}

En este trabajo, se analiza la dinámica espacio-temporal de los usos urbanos durante la segunda mitad del siglo XX en el entorno metropolitano de Alacant-Elx. A partir de fotogramas aéreos correspondientes a las fechas de 1956, 1985, 1998 y 2005, y mediante métodos de análisis cartográfico con sistemas de información geográfica, se han establecido los cambios a escala detallada (1:10.000). También se han aplicado diez indicadores para evaluar el nivel de sostenibilidad ambiental. Los resultados muestran la gran expansión de los usos urbanos y el consecuente retroceso de los agrícolas y forestales durante todo el periodo analizado. La superficie construida, que representaba 2.226 ha (un $2 \%$ del total) en 1956, alcanza 16.804 ha (un 15\%) en 2005. Además, el crecimiento se ha intensificado sustancialmente en el periodo 1998-2005.

Palabras clave: urbanización; dinámica espacio-temporal; indicadores de sostenibilidad; sellado antropogénico del suelo; áreas litorales mediterráneas.

Resum. Mig segle (1956-2005) de creixement urbà i pèrdua de sòl al litoral mediterrani espanyol. L'entorn metropolità d'Alacant-Elx

En aquest treball, s'hi analitza la dinàmica espacial i temporal dels usos urbans durant la segona meitat del segle XX a l'entorn metropolità d'Alacant-Elx. Partint de fotografies aèries corresponents a 1956, 1985, 1998 i 2005, i mitjançant mètodes d'anàlisi cartogràfica amb sistemes d'informació geogràfica, han estat establerts els canvis a escala de detall (1:10.000). També s'han aplicat deu indicadors per avaluar el nivell de sostenibilitat ambiental. Els resultats mostren la gran expansió dels usos urbans i el retrocés consegüent dels agrícoles i forestals al llarg del període analitzat. La superfície construïda, que representava 2.226 ha (un 2\% del total) l'any 1956, arriba a 16.804 ha (un 15\%) el 2005. A més, el creixement s'ha intensificat substancialment durant el període 1998-2005.

Paraules clau: urbanització; dinàmica espacial i temporal; indicadors de sostenibilitat; segellat antropogènic del sòl; àrees litorals mediterrànies. 
Résumé. Un demi-siècle (1956-2005) de croissance urbaine et dégradation du sol dans la côte méditerranéenne espagnole. Le milieu métropolitain d'Alacant-Elx

Cet article a pour objet l'analyse de la dynamique spatiale et temporale des utilisations urbaines durant la deuxième moitié du vingtième siècle dans le milieu métropolitain d'Alacant-Elx. Afin d'observer ces modifications à une échelle détaillée (1:10.000), la photointerprétation de photographies aériennes datées de 1956, 1985, 1998 et 2005, et l'analyse cartographique avec les systèmes d'information géographique ont été pris en compte. Dix indicateurs ont aussi été appliqués pour évaluer le niveau de durabilité environnementale. Les résultats obtenus montrent l'importance de la croissance urbaine pendant la période d'étude, spécialement le pourcentage élevée de la surface destinée à cette utilisation à l'issue de l'étude. En 1956, date d'initiation de l'analyse, l'utilisation urbaine a représenté 2.226 (un $2 \%$ de la surface totale). Cinquante ans après, l'utilisation urbaine a représenté 16.804 ha (un 15\%). Ce processus a été intensifié entre 1998 et 2005.

Mots clé: croissance urbaine; dynamique spatiale et temporales; indicateurs de développement durable; scellé artificiel du sol; côte méditerranéenne.

Abstract. Half a century (1956-2005) of urban growth and soil loss in the Mediterranean coastal area of Spain: The metropolitan area of Alacant-Elx

This paper analyses the spatial and temporal dynamics of urban land uses during the second half of the 20th century in the metropolitan area of Alacant-Elx. Through the interpretation of aerial photographs dating from 1956, 1985, 1998 and 2005, and map analysis based on geographic information systems, the changes at detailed scale $(1: 10,000)$ were established. Ten indicators were also used to assess the degree of environmental sustainability. The results highlight the intensity of urban growth from 1956 to 2005 and the reduction of agricultural and forest uses. In 1956, 2,226 ha (2\% of the total area) were built-up areas, whereas 16,804 ha $(15 \%)$ of the surface were occupied by urban uses in 2005; a process which significantly intensified during the 1998-2005 period.

Keywords: urbanization; spatial and temporal dynamics; sustainability indicators; soil sealing; Mediterranean coastal areas.

\author{
Sumario \\ Introducción Conclusiones \\ Metodología Referencias bibliográficas \\ Resultados
}

\title{
Introducción
}

En la cuenca mediterránea, los espacios urbanos concentran un elevadísimo porcentaje de población, actividades y recursos. En su expansión, consumen volúmenes crecientes de suelo, generalmente los destinados originariamente a usos agrícolas o forestales. Las áreas rurales experimentan la intensificación de cultivos en las zonas litorales y los valles fluviales y, al mismo tiempo, el abandono en las zonas montañosas (Gerard et al., 2010). Así, todos estos ámbitos se 
ven empujados a la reorganización espacial ante las profundas modificaciones económicas y demográficas que les afectan, con carácter claramente desigual. Al mismo tiempo, la densificación de la red viaria contribuye a los cambios por la expansión de determinados usos del suelo a lo largo de esos ejes. Generalmente, el fin último del uso del suelo es el aprovechamiento de los recursos naturales para las necesidades humanas, a veces a expensas de la degradación ambiental. Aunque, en conjunto, el uso del suelo es absolutamente esencial para la población, determinadas prácticas pueden degradar de forma significativa el medio y comprometer la sostenibilidad a largo plazo (Foley et al., 2005; OSE, 2006). Recientemente, la Agencia Europea de Medio Ambiente (EEA, 2010) ha detectado una serie de problemas que están ligados a los cambios de uso del suelo, entre ellos, por ejemplo, la pérdida de biodiversidad (sustitución de especies, fragmentación de hábitats, etc.), el cambio climático (alteración del ciclo del carbono, emisión de gases de efecto invernadero, alteración del albedo, etc.), la contaminación del aire y del agua (polución atmosférica, exceso de productos fitosanitarios, generación de residuos urbanos, etc.) o la degradación del edafosistema (sellado antropogénico, erosión, compactación, contaminación, salinización, etc.).

Desde la década de 1950, el litoral mediterráneo español ha experimentado importantes cambios en los usos y las coberturas del suelo. El crecimiento de las superficies artificiales ocasionado por la urbanización, la industrialización o la implantación de infraestructuras es, sin duda, el más remarcable. El sellado antropogénico del suelo (soil sealing, en la literatura anglosajona) anula el carácter multifuncional del recurso edáfico, ello constituye un tipo de degradación prácticamente irreversible (Prokop et al., 2011). El proceso ha tenido especial relevancia en los centros metropolitanos que concentran la mayor parte de la población, las actividades económicas y las principales infraestructuras y equipamientos (Serrano, 2005). En algunas ocasiones, el crecimiento urbano refleja no sólo un incremento cuantitativo de la población, sino también un cambio cualitativo en la utilización del territorio. En las áreas metropolitanas mediterráneas españolas, está comenzando a percibirse un fenómeno que hasta hace poco era exclusivo del mundo anglosajón (Muñoz, 2003). Es el caso de la urbanización dispersa (urban sprawl), muy ligada, en ocasiones, a la extensión y a la densificación de las vías de comunicación y a las dinámicas de desconcentración de la población urbana (Montiel, 2012). Este proceso ha sido ampliamente estudiado en Estados Unidos desde hace décadas (Johnson, 2001; Hasse y Lathrop, 2003), mientras que, en Europa, la detección de la relevancia de la dispersión urbana es más reciente (EEA, 2006; Kasanko et al., 2006; Arribas et al., 2011). Durante los últimos años, también ha surgido el interés por el tema en España (Muñiz et al., 2006; Delgado y García, 2009; Blanco, 2011; Parcerisas et al., 2012).

En España, existen ejemplos de trabajos que analizan la pérdida de suelo por sellado artificial ya en los años setenta (Zapata et al., 1975). No obstante, son escasas las aportaciones sobre este proceso hasta la última década. Así, cabe destacar los recientes trabajos en el litoral andaluz (Ojeda y Villar, 2006; 
Moreira, 2011), murciano (Acosta et al., 2007; Romero-Díaz et al., 2011) o catalán (Martí y Pintó, 2012). Se han publicado también, en los últimos años, varios estudios sobre la urbanización y la consiguiente pérdida del recurso edáfico en las zonas costeras de la Comunitat Valenciana. Así, a modo de ejemplo, Añó et al. (2005) analizan el sellado antropogénico del suelo en toda la provincia de Castellón, haciendo especial énfasis en la incidencia del proceso en la franja costera. Boira (2011), utilizando los datos aportados por el proyecto CORINE-Land Cover (años 1990, 2000 y 2006), se centra en el urbanismo expansivo en la Región Urbana de Valencia, entendida como la agregación de su área metropolitana estricta más las comarcas limítrofes. A escala mucho más detallada, Valera et al. (2011a) han investigado el crecimiento de las superficies construidas y la degradación de los suelos entre 1956 y 2006 en el municipio de Valencia. La misma línea de investigación, tanto temática como cronológica, se ha aplicado en el término municipal de Alicante (Valera et al., 2011b). También en el litoral alicantino, Navarro et al. (2012) han examinado el impacto del crecimiento urbano sobre el edafosistema en el municipio de Elche a partir de imágenes de satélite datadas entre 1978 y 2005.

A continuación, se analiza la distribución espacial y la dinámica temporal de cambio en los usos urbanos para cuatro fechas (1956, 1985, 1998 y 2005) en el área metropolitana de Alacant-Elx. Para esas mismas fechas y para los periodos entre ellas, se presentan y se analizan, también, los datos y las tendencias aportados por los resultados de los distintos indicadores de sostenibilidad ambiental que se explicitarán en el apartado sobre metodología. Los indicadores son medidas o estadísticas referidas a la magnitud, la intensidad o la variación de un factor o recurso (Recatalá, 2009). La utilidad de los mismos reside en que su aplicación permite mostrar las tendencias de cambio provocadas por procesos de degradación, así como las modificaciones en el estado de los recursos naturales, aportando un tipo de información útil en el proceso de toma de decisiones y en la propuesta de estrategias de desarrollo sostenible (Recatalá et al., 2009). La cartografía sobre usos y coberturas del suelo y sus cambios aporta una información de gran utilidad en la elaboración de este tipo de indicadores. El conjunto de resultados, especialmente la cartografía elaborada en este trabajo, permite construir una imagen aproximada de la dinámica durante el último medio siglo: la dimensión espacial, los ritmos temporales, así como las posibles causas y consecuencias de estos cambios.

\section{Metodología}

La gran mayoría de los trabajos que abordan el estudio de la dinámica de usos y coberturas del suelo, y especialmente los que se centran en la evolución de los usos urbanos, utilizan, como información de partida, datos procedentes de imágenes de percepción remota, ya sean fotografías aéreas o imágenes de satélite, aprovechando las potencialidades de los SIG (Treitz y Rogan, 2004). La conjunción de estas técnicas permite obtener información fácilmente actualizable del fenómeno estudiado y con gran precisión espacial. Así, a partir de 
imágenes correspondientes a las fechas de 1956, 1985, 1998 y 2005, y utilizando métodos de análisis cartográfico con SIG, se han obtenido los cambios acumulativos de los usos urbanos a escala detallada. Los fotogramas de los vuelos de 1956 (escala 1:33.000) del Servicio Geográfico del Ejército (SGE) y de 1985 (escala 1:30.000) del Ejército del Aire (CECAF) / Instituto Geográfico Nacional (IGN) fueron escaneados a alta resolución y ortorrectificados para su fotointerpretación a escala 1:10.000. La ortorrectificación se realizó identificando puntos de control sobre un modelo digital de elevaciones y dos ortofotos de 1998 (resolución de $1 \mathrm{~m}$ ) y 2005 (resolución de $0,5 \mathrm{~m}$ ), ambas realizadas por el Instituto Cartográfico Valenciano (ICV). Se obtuvieron, así, ortofotografías digitales georreferenciadas y sin deformaciones (Sánchez-Espeso, 2000). El mapa topográfico digital, escala 1:10.000, del ICV constituyó la base de referencia cartográfica para la incorporación de la información aportada por las imágenes de 1956, 1985, 1998 y 2005. La metodología está diseñada para incorporar otras fechas, lo cual permite la actualización constante y progresiva. A partir de esas imágenes en formato ráster, se realizó, mediante técnicas convencionales de fotointerpretación (Fricke y Wolff, 2002; Nasarre y Badia, 2006), la digitalización vectorial en pantalla teniendo en cuenta la tipología de usos y coberturas del suelo. En la leyenda cartográfica, se han distinguido dos clases de usos urbanos en función del mayor o menor porcentaje de vegetación o suelo desnudo en la matriz construida y una tercera clase no urbana (figura 1). Las clases urbanas están constituidas por superficies artificiales construidas y sus terrenos asociados (patios, jardines, etc.) destinadas a infraestructuras o actividades residenciales, industriales o comerciales, siempre que queden en el interior de unidades compactas de edificación, es decir, que puedan ser delimitadas por un polígono cerrado que las separe de las áreas dedicadas exclusivamente a usos agrícolas o forestales. También se consideran urbanas las áreas en construcción.

La extracción de la información se efectuó en dos niveles. En primer lugar, se realizó la base de datos geométricos, proceso de digitalización vectorial, teniendo en cuenta las clases de usos y coberturas del suelo. Con este fin, se digitalizaron en pantalla como líneas los límites de las unidades identificables en la ortofoto más reciente (2005). A partir de ellas, se construyó una topología de polígono arco y se asignó un identificador numérico a cada unidad. En segundo lugar, se construyeron las tablas de bases de datos asociadas, asignándose los identificadores de las tipologías de uso a los polígonos digitalizados. Las cartografías para las fechas anteriores se realizaron progresivamente mediante la adición, la sustracción de elementos o la modificación de atributos de la capa correspondiente a la fecha inmediatamente posterior disponible (figura 2). Este procedimiento permite optimizar la coherencia interna entre las distintas capas, minimizando en lo posible desplazamientos irreales en las cartografías que puedan ser contabilizados en el análisis como falsos cambios (Perdigao y Anonni, 1997).

La información obtenida fue revisada y corregida, tanto en gabinete como mediante visitas de campo. A tal efecto, se establecieron una serie de transectos 




Figura 1. Leyenda de usos urbanos del suelo para el entorno metropolitano de Alacant-Elx. Fuente: elaboración propia. 


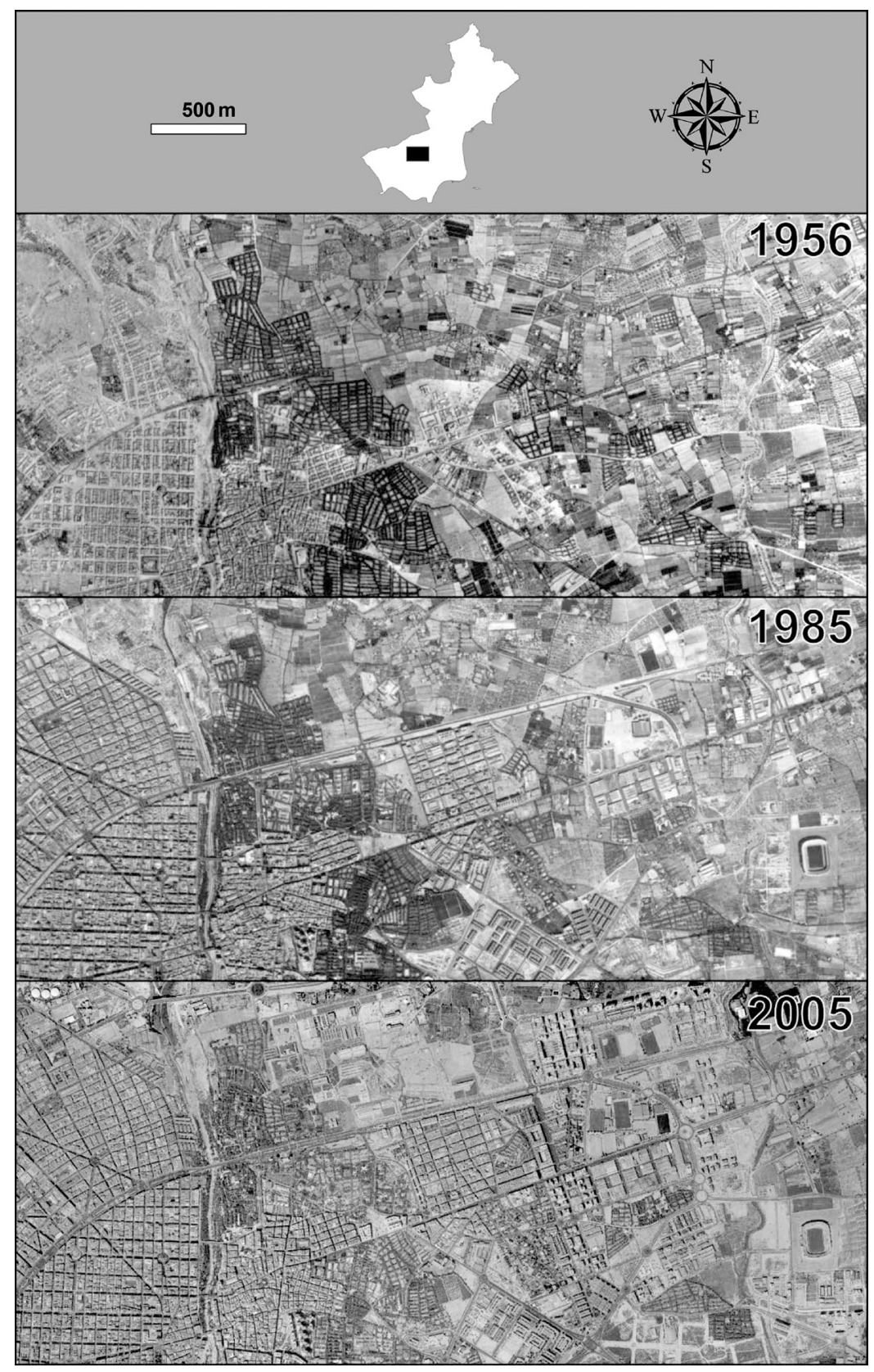

Figura 2. Ejemplo de ortofotografías de distintas fechas utilizadas para la edición posterior de la cartografía.

Fuente: elaboración propia. 
o itinerarios que cubren gran parte del área de estudio y en los que se realizó la verificación y corrección del premapa de usos. A partir de tablas cruzadas o matrices de confusión, se obtuvieron los resultados absolutos y relativos para cada clase en las distintas fechas analizadas. También por cruce de tablas se obtuvieron los datos de cambios de usos entre los distintos periodos considerados para evaluar la dinámica sincrónica y diacrónica de las transformaciones.

Para caracterizar la dinámica espacio-temporal de cambio de los usos y las coberturas del suelo, resulta fundamental la construcción de un sistema de indicadores que aporten información sintética de las tendencias de cambio. En Valera (2011) se desarrollaron y se aplicaron 19 indicadores agrupados en 6 áreas temáticas. En este trabajo, se presentan los resultados de 10 de ellos. El esquema está basado en los aplicados en 15 áreas urbanas europeas durante la realización del proyecto MOLAND (Monitoring Land Use Changes) (Kasanko et al., 2006). Más allá de algunas modificaciones puntuales en el proceso de cálculo, en este trabajo se han añadido otros indicadores que profundizan en el análisis.

El primer grupo de indicadores, «áreas construidas», se centra en la medida de elementos relacionados con la extensión y el crecimiento de las superficies construidas. Se contabilizan las magnitudes absolutas y relativas, se determina el rango y el ritmo de la dinámica, además, se dedica atención especial al primer kilómetro de costa, por su sensibilidad ambiental ante el proceso. Además de contabilizar los porcentajes relativos para cada tipo de superficie artificial, también se plasman el estado y las tendencias de mayor o menor dispersión y densidad que ha experimentado el uso urbano residencial. El segundo grupo de indicadores se centra en el consumo de suelo ocasionado por esas nuevas superficies construidas. Se determina, así, tanto el carácter agrícola o forestal de los usos antecedentes, como la cantidad de suelos con una capacidad de uso elevada o muy elevada que han desaparecido a consecuencia del proceso de sellado. Los indicadores sobre población aportan información de especial relevancia sobre el que es, sin duda, uno de los principales factores de cambio y transformación de los usos del suelo. Siguiendo esa línea, otro grupo («densidad urbana») hace hincapié en la relación existente entre la dinámica demográfica y el crecimiento de la superficie construida. La última área temática está integrada por un único indicador, que sintetiza el porcentaje superficial de aquellos espacios protegidos por sus valores naturales, patrimoniales y paisajísticos. A continuación, se muestra la definición, la fuente y el procedimiento de cálculo para la elaboración de los indicadores.

Superficie construida (SC): superficie total, en hectáreas, ocupada por las áreas construidas o en construcción. Indica la dimensión espacial absoluta del sellado artificial del suelo en una fecha determinada. Fuente: cartografía de usos y coberturas de elaboración propia. Procedimiento de cálculo: total de superficie construida, incluyendo las zonas urbanas de alta y baja densidad. 
Porcentaje de superficie construida (PSC): porcentaje de superficie construida respecto a la superficie total. Indica la dimensión espacial relativa del sellado artificial del suelo en una fecha determinada. Fuente: cartografía de usos y coberturas de elaboración propia. Procedimiento de cálculo:

$$
P S C=(S C / S T) \times 100
$$

Siendo $S C$ el total de superficie construida y $S T$, la superficie total.

Crecimiento de las superficies construidas (CSC): crecimiento total de la superficie construida durante el periodo considerado. Expresa la magnitud porcentual del cambio entre las dos fechas analizadas. Fuente: cartografía de usos y coberturas de elaboración propia. Procedimiento de cálculo:

$$
\left.C S C=\left(\left(S C_{1}-S C_{0}\right) / S C_{0}\right)\right) \times 100
$$

Siendo $S C_{1}$ la superficie construida en la fecha final y $S C_{0}$, la superficie construida inicial.

Crecimiento anual de las superficies construidas (ASC): ratio entre el crecimiento total de la superficie construida durante el periodo considerado y el número de años transcurridos. Indica el ritmo anual estimado del proceso. Fuente: cartografía de usos y coberturas de elaboración propia. Procedimiento de cálculo:

$$
A S C=\left(S C_{1}-S C_{0}\right) / t
$$

Siendo $S C_{1}$ la superficie en ha construida en la fecha más actual, $S C_{0}$, la superficie construida en la fecha inicial y $t$, el número de años transcurridos.

Porcentaje de superficie construida en el primer kilómetro de costa (PCK): porcentaje de superficie construida en el primer kilómetro de costa respecto al área total disponible en esa franja. Indica el grado de urbanización del litoral, normalmente asociado al sector turístico. Fuente: cartografía de usos y coberturas de elaboración propia. Procedimiento de cálculo:

$$
P C K=(S C K / S D K) \times 100
$$

Siendo $S C K$ el total de la superficie construida en el primer kilómetro de costa y $S D K$, la superficie total disponible en dicha franja.

Pérdida de suelos con elevada y muy elevada capacidad de uso (CAB): superficie construida sobre suelos con capacidad de uso muy elevada o elevada (clases A y B). Indica la magnitud absoluta de la pérdida de los mejores suelos agrícolas. Fuente: cartografía de usos y coberturas de elaboración propia. Cartografía de capacidad de uso de los suelos en la Comunidad Valenciana (COPUT, 1998). Procedimiento de cálculo: total de la superficie construida sobre suelos con capacidad de uso de clase A y B, en hectáreas. 
Crecimiento de la población (CP): cambio en la población del área de estudio entre dos fechas, en porcentaje. Indica la variación de la presión antrópica directa sobre el conjunto del territorio. Fuente: Instituto Nacional de Estadística (INE) e Instituto Valenciano de Estadística (IVE). Procedimiento de cálculo:

$$
C P=\left(\left(P_{1}-P_{0}\right) / P_{0}\right) \times 100
$$

Siendo $P_{1}$ el número de habitantes en la fecha más actual y $P_{0}$, en la fecha inicial.

Densidad demográfica (DP): población respecto a la superficie total del área de estudio. Indica la presión antrópica directa sobre el conjunto del territorio. Fuente: Instituto Nacional de Estadística (INE) e Instituto Valenciano de Estadística (IVE). Procedimiento de cálculo:

$$
D P=P / S T
$$

Siendo $P$ el número total de habitantes del área de estudio y $S T$, la superficie total de ésta en $\mathrm{km}^{2}$.

Superficie construida disponible por persona (SCP): superficie construida disponible por habitante, en $\mathrm{m}^{2}$ por persona. Indica la media de ocupación del territorio para usos urbanos por habitante. Fuente: Instituto Nacional de Estadística (INE) e Instituto Valenciano de Estadística (IVE). Fuente: cartografía de usos y coberturas de elaboración propia. Procedimiento de cálculo:

$$
S C P=S C / P
$$

Donde $S C$ es el total de superficie construida $\left(\mathrm{en}^{2}\right)$ en la fecha considerada y $P$, el número de habitantes.

Porcentaje de superficie protegida (PROT): porcentaje de superficie con alguna figura de protección (propuesta o aprobada) respecto a la superficie total del área de estudio. Indica la calidad para la conservación del territorio. Fuente: Conselleria de Medi Ambient, Territori i Habitatge. Europarc (www. europarc-es.org). Procedimiento de cálculo:

$$
P R O T=(P R T / S T) \times 100
$$

Siendo $P R T$ la superficie protegida y $S T$, la superficie del área de estudio. Las figuras de protección consideradas son: parques naturales, lugares de interés comunitario, zonas de protección especial para las aves, paisajes protegidos y parajes municipales.

\section{Resultados}

El área metropolitana de Alacant-Elx, con una superficie total de 112.565 ha y una población de 771.061 habitantes en 2010 (IVE), es la segunda en impor- 


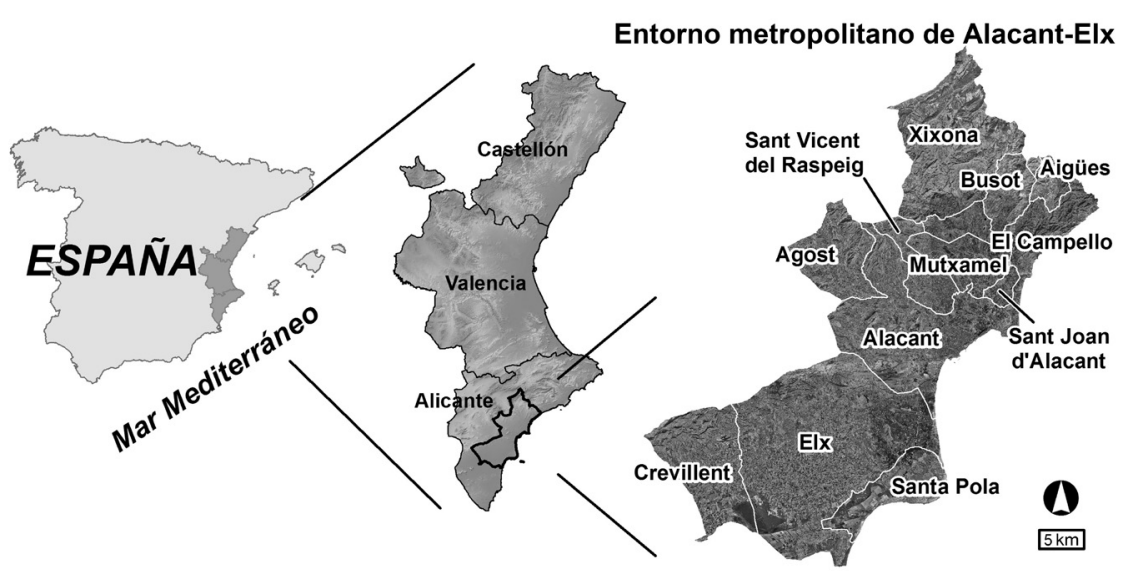

Figura 3. Localización del área de estudio.

tancia en la Comunitat Valenciana, por su potencial económico y demográfico. Los 12 municipios que, de acuerdo con COPUT (2000), conforman el área de estudio son: Agost, Aigües, Alacant, Busot, El Campello, Crevillent, Elx, Mutxamel, Sant Joan d'Alacant, Sant Vicent del Raspeig, Santa Pola y Xixona (figura 3). Durante el periodo cronológico analizado, las modificaciones económicas y demográficas que ha experimentado este entorno metropolitano se han plasmado sobre el territorio en una importante dinámica de cambio de los usos del suelo.

\section{La situación en 1956}

En la fecha inicial del análisis, 2.226 ha del entorno metropolitano corresponden a superficies construidas (SC), de modo que el porcentaje de las mismas (PSC) es de un 2\%. Alacant, Elx y Sant Vicent del Raspeig son los municipios con mayor superficie urbana, mientras que Busot, Xixona, Agost y Aigües son los que presentan menor superficie construida. El proceso de urbanización del litoral, ligado a la intensificación del sector turístico, está en una etapa incipiente, como demuestra que el porcentaje de superficie construida en el primer kilómetro de costa (PCK) sea tan sólo del 10\%. La densidad de población (DP) en 1956 presenta un valor bajo, de $206 \mathrm{hab} . / \mathrm{km}^{2}$. Atendiendo a la superficie construida disponible por persona (SCP), con un valor medio de 96 metros cuadrados construidos por habitante $\left(\mathrm{m}^{2} / \mathrm{hab}\right.$.), la ocupación del suelo para usos urbanos es bastante intensiva en comparación con los valores que, como veremos, se alcanzan en las fechas posteriores (tabla 1).

Se observa, por tanto, una situación inicial de claro predominio de los usos forestales y agrícolas frente a los urbanos, en una fecha cercana todavía a las dificultades económicas de la posguerra española. Todavía no se han producido las grandes transformaciones socioeconómicas de la segunda mitad del siglo XX 
Tabla 1. Indicadores aplicados en el entorno metropolitano de Alacant-Elx

\begin{tabular}{|c|c|c|c|c|}
\hline & 1956 & 1985 & 1998 & 2005 \\
\hline Superficie construida (SC) (ha) & 2.226 & 10.513 & 13.598 & 16.804 \\
\hline Porcentaje de superficie construida (PSC) & 1,98 & 9,34 & 12,08 & 14,93 \\
\hline $\begin{array}{l}\text { Porcentaje de superficie construida } \\
\text { en el 1er km de costa (PCK) }\end{array}$ & 10,05 & 29,01 & 37,75 & 44,67 \\
\hline Densidad demográfica (DP) (hab./km²) & 206 & 475 & 534 & 631 \\
\hline \multirow{2}{*}{$\begin{array}{l}\text { Superficie construida disponible por persona } \\
(\mathrm{SCP})\left(\mathrm{m}^{2} / \mathrm{hab} \text {.) }\right.\end{array}$} & 96,07 & 196,49 & 226,16 & 236,52 \\
\hline & 1956-2005 & 1956-1985 & 1985-1998 & $1998-2005$ \\
\hline $\begin{array}{l}\text { Crecimiento total de la superficie construida } \\
\text { (CSC) (\%) }\end{array}$ & 654,98 & 372,31 & 29,35 & 23,58 \\
\hline $\begin{array}{l}\text { Crecimiento anual de la superficie construida } \\
\text { (ASC) (ha/año) }\end{array}$ & 297,52 & 285,76 & 237,34 & 458,02 \\
\hline \multirow[t]{2}{*}{ Crecimiento de la población (CP) (\%) } & 206,65 & 130,93 & 12,38 & 18,17 \\
\hline & & & & $1985-2005$ \\
\hline \multirow{2}{*}{$\begin{array}{l}\text { Pérdida de suelos con elevada y muy elevada } \\
\text { capacidad de uso (CAB) (ha) }\end{array}$} & & & & 1.675 \\
\hline & & & & 2007 \\
\hline Porcentaje de superficie protegida (PROT) & & & & 18,18 \\
\hline
\end{tabular}

Fuente: elaboración propia.

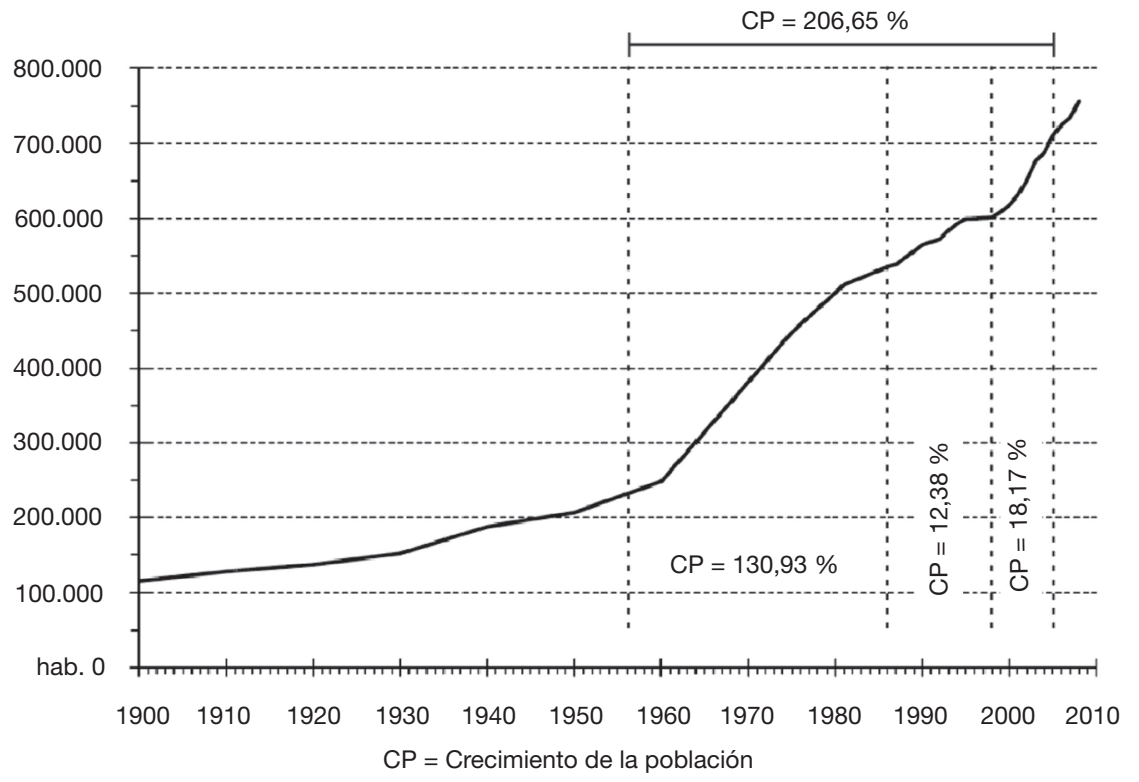

Figura 4. Evolución de la población (1900-2010) en el entorno metropolitano de Alacant-Elx. Fuente: elaboración propia a partir de datos oficiales de población del INE y del IVE. 
que encontrarán su principal momento de despegue a partir de 1960 y que son indisociables de la dinámica demográfica (figura 4).

\section{La gran expansión (1956-1985) y la relativa contención de la tendencia (1985-1998)}

El crecimiento demográfico (CP) del 131\% entre 1956 y 1985 explica, en gran medida, la dinámica experimentada por las superficies construidas durante el periodo analizado. Se alcanza, de este modo, en 1985, una densidad de población (DP) de $475 \mathrm{hab} . / \mathrm{km}^{2}$. No obstante, el crecimiento de las superficies construidas (CSC), con un valor del $372 \%$, es muy superior al de la población. Estos datos, así como los $196 \mathrm{~m}^{2} / \mathrm{hab}$. de superficie construida por persona (SCP), indican una ocupación del suelo más extensiva (tabla 1). De este modo, en 1985, la superficie construida (SC) alcanza las $10.513 \mathrm{ha}$, con un porcentaje (PSC) del 9\%. Aunque el proceso de expansión urbana no es constante en el tiempo, las 8.287 ha de incremento entre 1956 y 1985 suponen un crecimiento anual (ASC) de 286 ha/año. Los municipios con mayor superficie dedicada a usos urbanos son Elx, Alacant y Sant Vicent del Raspeig. En el otro extremo, se sitúan Aigües, Xixona y Agost (figura 5). La mayor urbanización del litoral, ligada al sector turístico, se refleja en un porcentaje de superficie construida en el primer kilómetro de costa (PCK) de un 29\%. El fuerte aumento experimentado por las zonas urbanas de baja densidad (tabla 2) puede considerarse como la principal causa del elevado ritmo de expansión de la superficie construida, tal como se ha puesto de manifiesto en trabajos anteriores (Valera et al., 2007; Valera et al., 2011c).

Tabla 2. Densidad de población y superficie de las zonas urbanas de alta densidad (UAD) y baja densidad (UBD) en los municipios del entorno metropolitano de Alacant-Elx.

\begin{tabular}{|c|c|c|c|c|c|c|c|c|c|c|c|c|}
\hline \multirow[b]{2}{*}{ Municipios } & \multicolumn{3}{|c|}{1956} & \multicolumn{3}{|c|}{1985} & \multicolumn{3}{|c|}{1998} & \multicolumn{3}{|c|}{2005} \\
\hline & $\begin{array}{l}\text { UAD } \\
\text { (ha) }\end{array}$ & $\begin{array}{l}\text { UBD } \\
\text { (ha) }\end{array}$ & $\begin{array}{c}\text { DP } \\
\left(\mathrm{hab} . / \mathrm{km}^{2}\right)\end{array}$ & $\begin{array}{l}\text { UAD } \\
\text { (ha) }\end{array}$ & $\begin{array}{l}\text { UBD } \\
\text { (ha) }\end{array}$ & $\begin{array}{c}\text { DP } \\
\left(\mathrm{hab} . / \mathrm{km}^{2}\right)\end{array}$ & $\begin{array}{l}\text { UAD } \\
\text { (ha) }\end{array}$ & $\begin{array}{l}\text { UBD } \\
\text { (ha) }\end{array}$ & $\begin{array}{c}\text { DP } \\
\left(\mathrm{hab} . / \mathrm{km}^{2}\right)\end{array}$ & $\begin{array}{l}\text { UAD } \\
\text { (ha) }\end{array}$ & $\begin{array}{l}\text { UBD } \\
\text { (ha) }\end{array}$ & $\begin{array}{c}\text { DP } \\
\left(\mathrm{hab} . / \mathrm{km}^{2}\right)\end{array}$ \\
\hline Agost & 18 & 19 & 37 & 70 & 83 & 57 & 130 & 92 & 60 & 218 & 115 & 69 \\
\hline Aigües & 7 & 7 & 53 & 13 & 13 & 18 & 15 & 22 & 30 & 16 & 43 & 43 \\
\hline Alacant & 621 & 374 & 570 & 1.7331 & 1.404 & 1.284 & 2.315 & 1.800 & 1.355 & 2.887 & 2.090 & 1.589 \\
\hline Busot & 6 & 3 & 20 & 8 & 168 & 22 & 8 & 195 & 44 & 10 & 254 & 71 \\
\hline Crevillent & 68 & 28 & 129 & 261 & 396 & 207 & 342 & 441 & 230 & 444 & 580 & 262 \\
\hline El Campello & 19 & 63 & 76 & 114 & 423 & 165 & 148 & 508 & 293 & 171 & 591 & 428 \\
\hline Elx & 259 & 399 & 203 & 1.0732 & 2.556 & 539 & 1.552 & 2.922 & 588 & 1.955 & 3.521 & 660 \\
\hline Mutxamel & 19 & 23 & 79 & 87 & 368 & 176 & 128 & 636 & 276 & 152 & 887 & 384 \\
\hline Sant Joan d'Alacant & 28 & 18 & 479 & 134 & 181 & 1.179 & 184 & 209 & 1.695 & 200 & 243 & 2.050 \\
\hline Sant Vicent del Raspeig & 79 & 70 & 204 & 322 & 656 & 634 & 449 & 777 & 905 & 552 & 825 & 1.148 \\
\hline Santa Pola & 45 & 9 & 107 & 200 & 128 & 227 & 301 & 268 & 302 & 345 & 461 & 438 \\
\hline Xixona & 22 & 23 & 37 & 70 & 52 & 45 & 82 & 73 & 45 & 146 & 100 & 46 \\
\hline Total & 1.190 & 1.036 & 206 & 4.0836 & 6.430 & 475 & 5.653 & 7.945 & 534 & 7.094 & 9.711 & 631 \\
\hline
\end{tabular}

Fuente: elaboración propia. 




Superficie construida

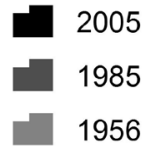

Espacios naturales protegidos

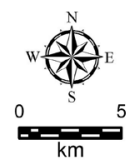

Figura 5. Síntesis del crecimiento urbano 1956-2005 en el entorno metropolitano de AlacantElx.

Fuente: elaboración propia. 
En 1998, en el entorno metropolitano, la superficie construida (SC) es de 13.598 ha y representa un porcentaje total (PSC) de un $12 \%$. Si bien el valor de $29 \%$ para el crecimiento de la superficie construida (CSC) muestra que el proceso continúa siendo de incremento de la misma, los cálculos considerando el tiempo transcurrido indican una desaceleración respecto a la tendencia de crecimiento del periodo 1956-1985. Así, el ritmo anual (ASC), para el periodo 1985-1998, es de 237 ha/año. La densidad de población (DP) es de $534 \mathrm{hab} . / \mathrm{km}^{2}$, pues el crecimiento de esta variable (CP) ha sido del $12 \%$. Procesos como la urbanización del litoral y la continuación de una ocupación del suelo cada vez más extensiva quedan reflejados, respectivamente, en el $38 \%$ de porcentaje construido en el primer kilómetro de costa (PCK) y los $226 \mathrm{~m}^{2} /$ hab. de superficie construida por persona (SCP). La franja costera del área metropolitana de Alacant presenta el mayor número de horas de sol de la Comunitat Valenciana (Pérez Cueva, 1994), ventaja climática que atrae a un gran número de visitantes y nuevos residentes a estos municipios costeros. A diferencia de lo que ocurre en las áreas periurbanas de Alacant y Elx, donde la construcción de segundas residencias y de viviendas principales suele estar vinculada a su población urbana, en esta franja litoral tienen mayor peso los residentes foráneos (Gozálvez et al., 1993).

En resumen, analizando la cartografía de cambio en los usos del suelo entre 1956 y 1985 (figura 5), la expansión de las zonas urbanas o superficies construidas, de alta o baja densidad, se ha producido en las siguientes áreas durante dicho periodo: en la periferia de los principales centros del área metropolitana (Alacant y Elx); alrededor de los ejes de comunicación más relevantes (las carreteras Crevillent-Elx-Alacant, Alacant-Sant Vicent del Raspeig y Elx-Santa Pola); en los llanos litorales con fuerte implantación del sector turístico (El Campello y Cap de l'Horta); en los llanos y piedemontes suavemente ondulados del sector septentrional del municipio de Alacant, y en los términos de Sant Vicent del Raspeig, Mutxamel, Sant Joan d'Alacant y El Campello. Para el periodo 19851998, se mantiene esa misma dinámica de crecimiento urbano, si bien algo más ordenada y limitada por la planificación municipal. Según Ponce y Ramos (2007), un buen número de las normativas sobre planeamiento urbanístico en los municipios litorales y prelitorales se redactaron tardíamente respecto al desarrollo del fenómeno turístico. Así, muchas grandes urbanizaciones son anteriores a los planes generales de ordenación urbana (PGOU) respectivos, que no harían más que legalizar a posteriori las irregularidades en la ocupación del suelo.

\section{La aceleración del crecimiento hasta 2005}

En 2005, la fecha más reciente analizada, la superficie construida alcanza las 16.804 ha, con un porcentaje (PSC) de un 15\%. Por clases de usos, 7.094 ha corresponden a zonas urbanas de alta densidad, frente a las 9.711 ha representadas por la urbanización de baja densidad. El crecimiento de la superficie construida (CSC) ha sido, por tanto, considerable, pues se cuantifica en un $24 \%$. El ritmo anual (ASC) durante todo el periodo 1998-2005, de 
458 ha/año, ilustra mejor la aceleración del proceso en esta última etapa analizada. Si bien el crecimiento demográfico (CP), con un valor del $18 \%$, es superior al del periodo anterior y permite que la densidad de población (DP) se sitúe en 631 hab./ $\mathrm{km}^{2}$, la relación entre las variables construcción versus población sigue siendo favorable a la primera. El incremento de la superficie construida por persona (SCP) supone un buen ejemplo de ello, pues alcanza, en 2005, los $237 \mathrm{~m}^{2} / \mathrm{hab}$. La localización de estos cambios se corresponde estrechamente con la apuntada anteriormente. Las manchas urbanas continúan extendiéndose en torno a las precedentes, especialmente junto a las principales vías de comunicación, las nuevas zonas industriales y las grandes áreas residenciales. Es el caso, respectivamente, de la autovía A-7; las carreteras Crevillent-Elx y Elx-Alacant; los polígonos industriales de Elx y Alacant, y las urbanizaciones de baja densidad al noreste de esta última ciudad y en la Sierra de Santa Pola. Los datos muestran que cerca de la mitad de la franja litoral, concretamente el $45 \%$, se encuentra ya construida (PCK). Las superficies construidas en 1956 se limitaban a los núcleos históricos de población y a algunas edificaciones dispersas ligadas a la actividad agrícola o a las fases más tempranas del turismo de sol y playa. En la última fecha de análisis, las manchas urbanas se han ido extendiendo desde estos puntos iniciales, preferentemente junto a las principales vías de comunicación y conectadas, por tanto, a los grandes centros metropolitanos: Alacant y Elx (Martí y García, 2009). Además, entre estas dos ciudades, han ido apareciendo grandes zonas industriales. En resumen, se puede afirmar que las tendencias de los intervalos anteriores se han mantenido e incluso acelerado. Las áreas económica y demográficamente más potentes son las que han experimentado mayores transformaciones, si bien una ocupación del territorio cada vez más extensiva y menos densa, junto a la continuación de los procesos de suburbanización, hacen que la expansión en «mancha de aceite» tienda a afectar a áreas cada vez más alejadas de los polos y de los ejes de crecimiento principales (figura 6). Muñiz et al. (2006) identificaron, en una fecha cercana al fin del «boom inmobiliario» español, las principales causas de la dispersión urbana en Europa. Entre ellas, las que han podido tener mayor incidencia en el entorno metropolitano de Alacant-Elx son la popularización de las segundas residencias, la facilidad de acceso a los créditos hipotecarios gracias a los bajos tipos de interés y el blanqueo de capitales mediante la compra de propiedades inmobiliarias provocado por la implantación del euro.

Además, tal como señala Burriel (2008 y 2009), el planeamiento urbanístico municipal ha tramitado expansiones urbanas exageradas que han propiciado la desmesurada expansión urbanística en la Comunitat Valenciana. Esta situación se ha amparado en la insuficiencia del ordenamiento territorial supramunicipal y la ausencia de medidas limitadoras del crecimiento en las sucesivas modificaciones de la legislación autonómica. Desde este punto de vista, el Plan de Acción Territorial del Entorno Metropolitano de Alacant-Elx (PATEMAE) puede considerarse más un compendio de directrices orientativas que un instrumento de ordenación del territorio o de coordinación de la planificación urbanística de los diferentes municipios. 


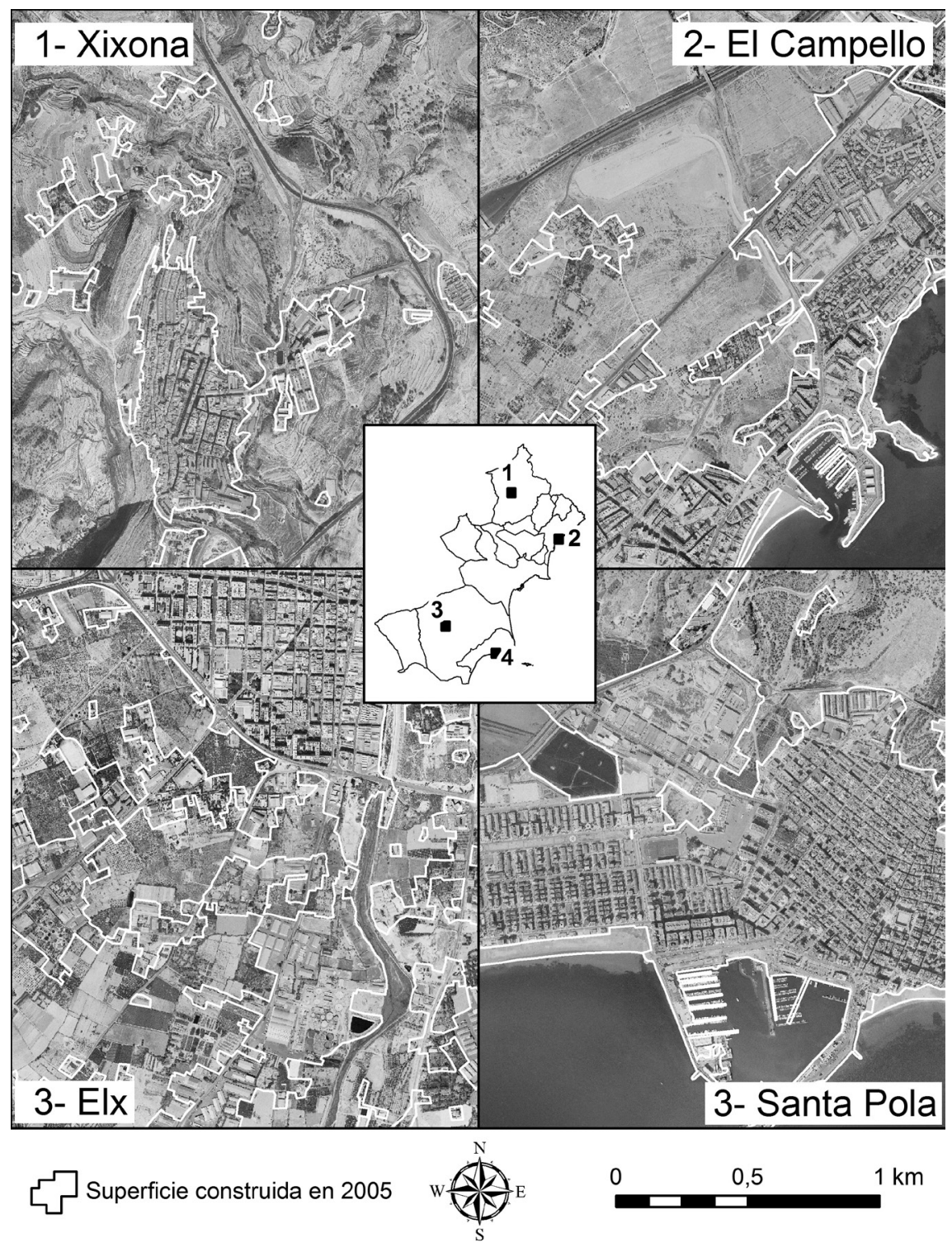

Figura 6. Ejemplos de diferentes procesos de expansión urbana en Xixona, El Campello, Elx y Santa Pola.

Fuente: elaboración propia. 
Puesto que la única cartografía disponible sobre capacidad de uso de los suelos fue generada a partir de finales de los ochenta, sólo hemos registrado datos de pérdida de suelos con elevada y muy elevada capacidad de uso desde 1985 hasta nuestros días. Los valores de pérdida de suelos con elevada y muy elevada capacidad de uso (CAB), de 1.675 ha en un periodo de apenas 20 años, muestran la gran incidencia del crecimiento de la superficie construida sobre este recurso. Paralelamente, el desarrollo urbanístico y el crecimiento económico frente a unos recursos limitados plantean otra problemática profunda en cuanto al modelo de gestión de los recursos hídricos (Juárez, 2004).

\section{Conclusiones}

Durante cerca de 50 años, se ha producido un espectacular incremento de la superficie construida (SC), que pasa de 2.226 ha a 16.804 ha. Se ha contabilizado un crecimiento total (CSC) del 655\%, con un ritmo anual (ASC) de 298 ha/año. Si bien la dinámica demográfica es, con un crecimiento (CP) del $207 \%$, en buena medida responsable de estos cambios, la comparación con el crecimiento de la superficie construida (CSC) y los valores por habitante (SDP) indican que, durante el último medio siglo, la ocupación del territorio por los procesos de urbanización ha sido cada vez más extensiva. No es ajena a este hecho la importancia de las zonas urbanas de baja densidad, ligadas en muchos casos a los fenómenos de la segunda residencia y al turismo litoral. El sector turístico ha tenido gran incidencia en la urbanización de la franja costera, especialmente en los municipios de El Campello y Santa Pola. Así, el porcentaje de superficie construida en el primer kilómetro de costa (PCK) se ha incrementado desde el $10 \%$ en 1956 hasta el 45\% en 2005. Respecto al porcentaje de superficie protegida (PROT), en 2007, es del 18\%. Si esa parte del entorno metropolitano, con limitaciones considerables a priori para la urbanización, se considerase fuera del análisis, las implicaciones de la dinámica de crecimiento urbano durante todo el periodo en el área de estudio serían incluso más importantes.

El proceso de sellado antropogénico del suelo, creciente durante todo el periodo analizado, se ha acelerado sustancialmente entre 1998 y 2005, con un valor del crecimiento anual de las superficies construidas (ASC) de 458 ha/año. Aunque con esos datos cabría vaticinar una continuación de la dinámica a corto y medio plazo, las perspectivas futuras han adquirido un elevado grado de indefinición ligado a la desaceleración del mercado de la vivienda, y en general de la economía desde aproximadamente la segunda mitad de 2007. El frenazo del sector inmobiliario y el exceso de la oferta de suelo urbano y urbanizable aprobados o en tramitación por muchas administraciones locales han propiciado que la Administración autonómica haya redactado, en los últimos años, varios planes territoriales supramunicipales. Estos planes contemplan la protección o preservación de determinados espacios por sus valores ambientales, paisajísticos o históricos, y consideran la necesidad de limitar el crecimiento urbanístico dentro de unos parámetros de sosteni- 
bilidad ambiental asumibles. Existen claras divergencias o contradicciones entre el modelo territorial y la planificación urbanística de la última década y las propuestas de contención del crecimiento actuales. Ante la incógnita de la duración y posibles soluciones de la crisis económica y financiera en España, resulta difícil aventurar la tendencia futura de la dinámica de los usos y las coberturas urbanas del suelo en áreas metropolitanas de la Comunitat Valenciana.

¿Se consolidarán los planes territoriales de protección ambiental y paisajística que se han propuesto en esta coyuntura recesiva para el mercado inmobiliario español? ¿O continuará el modelo de crecimiento urbano vigente durante buena parte del último medio siglo y que ha motivado que un elevado porcentaje de los suelos con mayor capacidad de uso en la región hayan sido degradados o destruidos por el proceso de sellado antropogénico? La elección de uno u otro escenario puede determinar la mayor o menor sostenibilidad ambiental en las áreas metropolitanas de la Comunidad Valenciana y, consecuentemente, del entorno metropolitano de Alacant-Elx.

\section{Referencias bibliográficas}

Acosta, J.A.; Faz, A. y Martínez-Martínez, S. (2007). «Crecimiento urbano e industrial en la ciudad de Murcia y alrededores entre 1956 y 1999: Cambios en los usos del suelo». En: Bellifante, N. y JordÁn, A. (eds.). Tendencias actuales de la ciencia del suelo. Sevilla: Universidad de Sevilla, 895-901.

AÑo, C.; PASCUAL, J.A. y SÁNCHEZ, J. (2005). «Capacidad de uso y sellado antropogénico del suelo en la franja litoral de la provincia de Castellón». Investigaciones Geográficas, 38, 65-77.

ARribaS, D.; NijKAmp, P. y SChOlten, H. (2011). «Multidimensional urban sprawl in Europe: A self-organizing map approach». Computers, Environment and Urban Systems, 35, 263-275

Blanco, M. (2011). Aplicación de indices para la cuantificación del «urban sprawl» en Valladolid y su entorno. Trabajo de fin de máster sobre tecnologías de la información geográfica. Universidad Complutense de Madrid.

BoIRA, J.V. (2011). «Transformaciones territoriales en la Región Urbana de Valencia (1990-2006): Ejes metropolitanos y cambios de usos del suelo». En: GoZÁLVEZ, V. y MARCO, J.A. (eds.). Urbanismo expansivo, de la utopía a la realidad. Libro deActas del XXII Congreso de Geógrafos Españoles. Alicante: Universidad de Alicante, 79-90.

BuRRIEL, E. (2008). «La década prodigiosa del urbanismo español (1997-2006)». Scripta Nova: Revista Electrónica de Geografía y Ciencias Sociales [en línea]. Barcelona: Universidad de Barcelona, 1 de agosto de 2008, XII (270), 64. <http://www.ub.es/ geocrit/sn/sn-270/sn-270/sn-270-64.htm>.

- (2009). «Los límites del planeamiento urbanístico municipal. El ejemplo valenciano». Documents d'Anàlisi Geogràfica, 54, 33-54.

COPUT (1998). El suelo como recurso natural en la Comunidad Valenciana. Valencia: Conselleria de Obras Públicas, Urbanismo y Transportes. Generalitat Valenciana. Territori, 8. 
- (2000). El entorno metropolitano de Alacant-Elx: reconocimiento territorial. Valencia: Conselleria de Obras Públicas, Urbanismo y Transportes. Generalitat Valenciana. Territori, 9.

Delgado, B. y GARCÍA, A. (2009). «Una aproximación a los nuevos paisajes de la metápolis en Andalucía». Scripta Nova: Revista Electrónica de Geografía y Ciencias Sociales [en línea]. Barcelona: Universidad de Barcelona, 15 de agosto de 2009, XIII (297). <http://www.ub.es/geocrit/sn/sn-297.htm>.

EEA (2006). Urban sprawl in Europe. The ignored challenge. EEA Report 10/2006. Copenhague: European Environment Agency.

- (2010). The European Environment - State and Outlook 2010: Land Use. Copenhague: European Environment Agency.

Foley, J.A.; Defries, R.; Asner, G.P.; BARford, C.; Bonan, G. et al. (2005). «Global Consequences of Land Use». Science, 309, 570-574.

Fricke, R. y WOlfF, E. (2002). "The MURBANDY Project: development of land use and network databases for the Brussels area (Belgium) using remote sensing and aerial photography». International Journal of Applied Earth Observation and Geoinformation, 4 (1), 33-50.

Gerard, F.; Petit, G.; Thompson, A.; Brown, N. et al. (2010). «Land cover change in Europe between 1950 and 2000 determined employing aerial photography». Progress in Physical Geography, 34 (2), 183-205.

Gozálvez, V.; Ponce, G.; Costa, J.; Canales, G. y Navarro, J.R. (1993). «Los espacios periurbanos en el área de Alicante-Elche (España)». Investigaciones Geográficas, 11, 171-188.

HASSE, J.E. y LATHROP, R.G. (2003). «Land resource impact indicators of urban sprawl». Applied Geography, 23, 159-175.

JoHnson, M. P. (2001). «Environmental impacts of urban sprawl: a survey of the literature and proposed agenda». Environment and Planning A, 33, 717-735.

JuÁrEZ, C. (2004). «Sistemas de indicadores de sostenibilidad y desarrollo turístico. Aplicación a la comarca del Bajo Segura (Alicante)». Investigaciones Geográficas, 33, 17-38.

Kasanko, M.; Barredo, J.I.; Lavalle, C.; Mccormick, N.; Demicheli, L.; Sagris, V. y Brezger, A. (2006). «Are European cities becoming dispersed? A comparative analysis of 15 European urban areas». Landscape and Urban Planning, 77, 111-130.

Martí, P. y García, M. C. (2009). "Los procesos de dispersión y concentración territorial en Alicante y su entorno». En: International Conference Virtual City and Territory. 5th International Conference Virtual City and Territory, Barcelona, 2, 3 and 4 June 2009. Barcelona: Centre de Política de Sòl i Valoracions, 13-24.

Martí, C. y Pintó, J. (2012). «Cambios recientes en el paisaje litoral de la Costa Brava». Documents d'Anàlisi Geogràfica, 58 (2), 239-264.

Montiel, A. (2012). «Expansión metropolitana y agricultura periurbana: Tensiones y oportunidades en L'Horta de Valencia». En: ROMERO, J. y FrAnCÉs, M. (eds.). La Huerta de Valencia: Un paisaje cultural con futuro incierto. Valencia: Publicacions de la Universitat de València, 137-157.

Moreira, J.M. (2011). «Urbanismo expansivo: de la utopía a la realidad. Reflexiones desde la información ambiental». Ponencia presentada en el XXII Congreso de Geógrafos Españoles. Alicante, octubre, 31.

MuÑIZ, I.; GarCía, M.A. y Calatayud, D. (2006). Sprawl: definición, causas y efectos. Working Paper, 06.03. Barcelona: Universitat Autònoma de Barcelona. 
MuÑoz, F. (2003). «Lock living: Urban sprawl in Mediterranean cities». Cities, 20 (6), 381-385.

NASARRE, M.E. y BADIA, A. (2006). «Una aproximación al crecimiento de áreas urbanas a través de fotografía aérea y de sistemas de información geográfica: La ciudad de Terrassa como caso de estudio». Cuadernos Geográficos de la Universidad de Granada, 39, 185-201.

NAvarro, J.; MelÉndez-PAstor, I. y Gómez, I. (2012). «Impact of three decades of urban growth on soil resources in Elche (Alicante, Spain)». Spanish Journal of Soil Science, 2 (1), 55-69.

OjeDA, J. y Villar, A. (2006): «Evolución del suelo urbano/alterado en el litoral de Andalucía (Еspaña): 1998-2002». Geofocus, 7, 73-99.

OSE (2006): Cambios de ocupación del suelo en España. Implicaciones para la sostenibilidad. Estudio realizado a partir del proyecto CORINE Land Cover. Informe del Observatorio de la Sostenibilidad en España (OSE). Madrid: Mundiprensa.

Parcerisas, L.; Marull, J.; Pino, J.; Tello, E.; Coll, F. y Basnou, C. (2012). "Land use changes, landscape ecology and their socioeconomic driving forces in the Spanish Mediterranean coast (El Maresme County, 1850-2005)». Environmental Science \& Policy, 23, 120-132.

Perdigao, V. y AnONni, A. (1997). Technical and methodological guide for updating CORINE land cover database. EUR 17288. Bruselas-Luxemburgo: European Commission.

Pérez-Cueva, A.J. (coord.) (1994). Atlas climático de la Comunidad Valenciana. Valencia: Conselleria de Obras Públicas, Urbanismo y Transportes. Generalitat Valenciana.

Ponce, G. y Ramos, A. (2007). «La ciudad suburbana en los territorios del turismo litoral en la provincia de Alicante». En: Grupo de GeOgrafía URbana de LA AGE: Los procesos urbanos posfordistas. VIII Coloquio y jornadas de campo de Geografía Urbana. Palma de Mallorca: Ministerio de Educación y Ciencia. Subdirección General de Información y Publicaciones, 399-415.

Prokop, G.; JobStMAnn, H. y SchÖnbaUER, A. (2011). Overview of best practices for limiting soil sealing or mitigating its effects in EU-27. Viena: Environment Agency Austria - European Commission.

ReCATALÁ, L. (dir.) (2009). Indicadores e Indices Integrados en la Agenda 21 Local para la Evaluación de la Calidad Ambiental en Áreas Afectadas por Desertificación del Ambito Mediterráneo. Valencia: Fundación Biodiversidad. Universitat de Valencia.

Recatalá, L.; AÑó, C.; Valera, A. y SÁnCHeZ, J. (2009). «Sistema de indicadores para evaluar la calidad ambiental y la desertificación en la Comunidad Valenciana». Investigaciones Geográficas, 50, 5-18.

Romero-Díaz, A.; Belmonte, F.; Docampo, A.M. y Ruiz, J.D. (2011). «Consecuencias del sellado de los suelos en el Campo de Cartagena (Murcia)». En: GOZÁlveZ,V. y MARCO, J.A. (eds.). Urbanismo expansivo, de la utopía a la realidad. Libro de Actas del XXII Congreso de Geógrafos Españoles. Alicante: Universidad de Alicante, 617-628.

SÁNCHEZ-ESPESO, J.M. (2000). «Análisis del proceso de rectificación de una imagen aérea de eje vertical para obtener una ortoimagen digital». Mapping, 64, 20-32.

SERrANO, A. (2005). «La problemática supramunicipal del modelo territorial del siglo XXI: Áreas metropolitanas y regiones funcionales urbanas». Territorio y Desarrollo Local, marzo, 11-16. 
Treitz, P. y Rogan, J. (2004). «Remote sensing for mapping and monitoring land-cover and land-use change: An introduction». Progress in Planning, 61 (4), 269-279.

VAlera, A. (2011). Dinámica espacio-temporal de usos y cubiertas del suelo en áreas metropolitanas de la Comunidad Valenciana. Valencia: Servei de Publicacions de la Universitat de València.

VAlera, A.; AÑó, C. y SÁnCHEZ, J. (2007). «Crecimiento urbano (1956-1998) en el entorno metropolitano de Alacant-Elx (Comunidad Valenciana)». Boletín de la $A G E, 44,169-186$.

- (2011a). «Cincuenta años (1956-2006) de crecimiento urbano y degradación de suelos por sellado antropogénico en el término municipal de Valencia». Anales de Geografía de la Universidad Complutense, 31 (2), 177-191.

- (2011b). «Crecimiento urbano (1956-2005) y sellado antropogénico del suelo en el municipio de Alacant». Serie Geográfica, 17, 97-108.

- (2011c): "Cambios en los usos y coberturas del suelo en el municipio de Elx (19562005)». Estudios Geográficos, 72 (271), 681-703.

Zapata, M.; Sempere, A.J. y Calvo, F. (1975): «El terreno fértil como recurso escaso. Un ejemplo de despilfarro: la huerta de Murcia». Revista de Estudios Agrosociales, 90, 189-204. 